\title{
Research Paper: Evaluation of Recurrence Rate and Risk Factors Affecting Recurrence of Recurrent Shoulder Dislocation in Kashani Hospital in 2017-2018
}

\author{
Hossein Akbari Aghdam ${ }^{1}$,, Mohammad Dehghani' ${ }^{1}$ Parisa Karimi2 ${ }^{2 *}$ (]) \\ 1. Department of Orthopedic Surgery, School of Medicine, Ayatollah Kashani Hospital, Isfahan University of Medical Sciences, Isfahan, Iran.
}

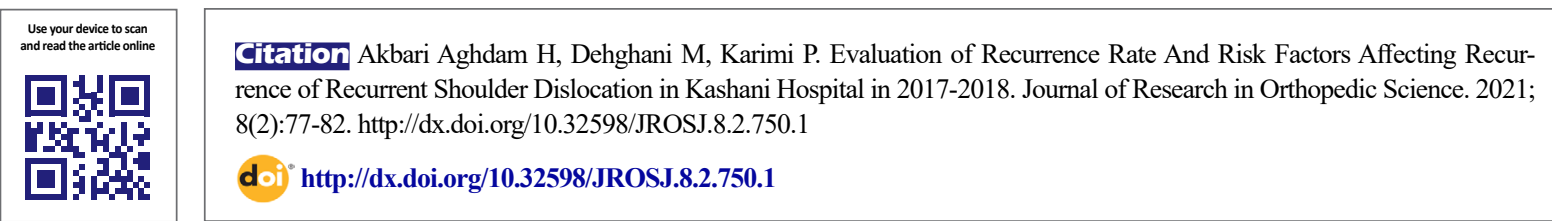

\section{(c) (i) (3)}

Article info:

Received: 30 Dec 2020

Revised: 25 Mar 2021

Accepted: 03 Apr 2021

Available Online: 01 May 2021

Keywords:

Shoulder Dislocation,

Recurrent, predicting factor

\begin{abstract}
A B S T RA C T
Background: In this article, the prevalence of recurrent anterior dislocation of the shoulder and the effect of factors such as age, occupation, primary cause and gender on it have been investigated.

Objectives: This study aimed to investigate the factors related to the frequency of recurrent anterior shoulder dislocation in clients of the Orthopedic Ward of Kashani Hospital, Isfahan City, Iran, in 2017-2018.

Methods: The present research is a cross-sectional study. The study population comprised all patients with traumatic and anterior shoulder dislocation referred to Kashani Hospital during 2017-2018. The sampling method in the present study was census. The patients were asked by phone or in person after their presence about the recurrences of dislocations between the beginning of 2017 and the end of 2018. The obtained data were analyzed in SPSS version 25.

Results: Out of 256 patients, $22 \%$ had a recurrence of dislocation. The recurrence rate of dislocation in less than 20 years patients was $40 \%$, and in 20 to 40 years was $63 \%$. The highest recurrence rate of dislocation was reported in the age group of 20 to 40 years in the present study. Based on the present study results, the recurrence rate of dislocation in the age-group of 20-40 years was significantly higher than in other groups. There was no significant relationship between gender and recurrence of dislocation in the subjects $(\mathrm{P}>0.05)$. Significance was observed in the primary cause and type of occupation in recurrence of dislocation $(\mathrm{P}<0.05)$.

Conclusion: The recurrence rate of dislocation in the patients who suffered from dislocations for the first time was $22 \%$. Based on the results, the rate of recurrence of dislocation in the present study was lower than the rate of recurrence of dislocation in similar studies.
\end{abstract}

\section{* Corresponding Author:}

Parisa Karimi, $M D$.

Address: Department of Orthopedic Surgery, School of Medicine, Ayatollah Kashani Hospital, Isfahan University of Medical Sciences, Isfahan, Iran. Phone: +98 (0918) 5628905

E-mail: parisak593@gmail.com 


\section{Introduction}

$\mathbf{T}$

he shoulder joint is one of the largest joints in the human body with the greatest range of motion. Therefore, the shoulder joint is the most common joint that is dislocated, and usually, $2 \%$ of people suffer from this

dislocation.

An anterior dislocation occurs when a strong force is applied to the shoulder in the external rotation and abduction. The shoulder joint can be dislocated in various directions, of which anterior dislocation is the most common type [1].

Dislocation of the shoulder joint is commonly recurrent. This instability of the shoulder reduces the patient's activities. Also, this dislocation is prone to recurrence (instability). There are several reasons for its occurrence [2]. Therefore, considering the importance of the issue, it is essential to identify the recurrence rate of dislocation and risk factors for the recurrence of dislocation [3].

In a study, the presence of a defect in the glenoid cavity and relaxation of the ligaments, especially young and professional athletes, were mentioned as risk factors for recurrent dislocation $[4,5]$. In another study, $75 \%$ of those treated conservatively had recurrent dislocations, compared with $11 \%$ of those who underwent surgery. This study showed that conservative treatment in young patients increases the risk of re-dislocations [6]. In a review study in 1956 on 500 patients with anterior dislocation, $99 \%$ of patients were between 10 and 20 years old. It was also shown that the rate of recurrent dislocation was $100 \%$ in patients under 10 years of age and $94 \%$ in patients aged 10-20 years [7, 8]. In another review study on 573 patients, the rate of re-dislocation in people under 20 years old was $90 \%$, in $20-40$ years old $60 \%$ and over 40 years old $10 \%$ [2].

Although shoulder dislocation has long been recognized as a disorder, there is no agreement on the length of the course and the position of immobilization to prevent recurrent dislocation. Recommendations ranged from no immobilization to immobilization for 8 weeks [3]. Rowe and Sakellarides found no evidence that immobilization was effective for more than 3 weeks. Maran et al. described 21 skeletally immature patients who had been treated for 15 years. All patients had re-dislocations at least once. Immobilization for more than 6 weeks did not affect re-dislocations. Henry and Genung found that the rate of re-dislocation was $90 \%$ in patients who were immobilized and $85 \%$ in patients who were not immo- bilized. It showed that immobilization did not affect redislocation [2]. In a review study of 252 patients aged $15-35$ years, $55.7 \%$ of patients had another dislocation in the first year after dislocation and $66.8 \%$ in the first two years after dislocation, which was higher in the lower buttocks [1]. Numerous studies have shown that young age, closed posture, and being an athlete are effective in the recurrence of shoulder dislocations [9-13].

\section{Study objectives}

The present study aimed to investigate the factors related to the frequency of recurrent anterior shoulder dislocation in clients of the Orthopedic Ward of Kashani Hospital, Isfahan City, Iran, in 2017-2018.

\section{Methods}

The present research is a cross-sectional study conducted in Kashani University Hospital, Isfahan City, Iran, during 2017-2018. The study population comprised all patients with traumatic and anterior shoulder dislocation referred to Kashani Hospital during 2017-2018. The inclusion criteria include patients with traumatic and anterior shoulder dislocation, having the first dislocation, and consent to participate in the study. The exclusion criteria include patients older than 60 , history of shoulder surgery, posterior dislocation and the presence of deformity in the shoulder and dissatisfaction with the study continuation or lack of information, recurrent dislocations, and fracture dislocation.

The sampling method was census so that all people referred to Kashani Hospital with traumatic and anterior shoulder dislocation during the years 2017-2018 were enrolled. First, by referring to the medical records of Kashani Hospital, the patients who are eligible to enter the study were extracted. Then the demographic characteristics of the patients were obtained from the file. Shoulder dislocation should be anterior and traumatic and should not occur spontaneously. It must happen because of traumas, including falls, sports activities, and accidents. The patients were then divided into age groups of less than 20 years, $20-40$ years, $40-60$ years, and more than 60 years. We had no patients under 10 years old with a shoulder dislocation and very few cases above 60 years. The patients were then asked by phone or in person about the presence or absence and the number of recurrences of dislocations between 2017-2018. After collecting information in a checklist, the data were entered into SPSS v. 20 and presented in tables and graphs by central and dispersion indices for qualitative variables. Also, quantitative variables are analyzed by 
the independent t-test, Chi-square test, and finally, logistic regression.

\section{Results}

Overall, 389 patients were identified and examined in the present study. Out of 389 patients, 101 were hospitalized due to recurrence of dislocation and excluded from the study. Also, 32 patients were excluded from the study due to lack of follow-up. Therefore, the information of 256 patients who suffered a dislocation for the first time was evaluated in the present study.

Table 1 and Table 2 present the descriptive characteristics of the 256 patients studied. The Mean \pm SD age of the subjects was $35.64 \pm 18.58$ years. Also, the Mean \pm SD duration of follow-up was $3.1 \pm 1.26$ years.
About $90 \%$ of the subjects were men, and approximately $80 \%$ were employees, self-employed, or students. Falling was the most common cause of dislocation in the subjects. About $22.6 \%$ of patients had a recurrence of dislocation. Table 3 presents the relationship between recurrence rate and demographic variables of gender, occupation, and primary cause. According to Table 3, there was no significant relationship between gender and recurrence of dislocation in the subjects $(\mathrm{P}>0.05)$. However, there was a significant difference in the primary cause and recurrence of dislocation $(\mathrm{P}<0.05)$. Table 4 shows the relationship between age and duration of immobility and recurrence of dislocation in the subjects. According to Table 4, the mean age of people with recurrence of dislocation was significantly low $(\mathrm{P}<0.05)$. Also, the mean duration of immobility in people with recurrent dislocation was significantly low $(\mathrm{P}<0.05)$.

Table 1. Determining the fequency distribution of demographic characteristics of the subjects

\begin{tabular}{|c|c|c|}
\hline \multicolumn{2}{|c|}{ Qualitative Variables } & \multirow{2}{*}{$\begin{array}{c}\text { No. (\%) } \\
232 \text { (90.6) }\end{array}$} \\
\hline & Male & \\
\hline Gender & & \\
\hline & Female & $24(9.4)$ \\
\hline \multirow{7}{*}{ Job } & Retired & $7(2.7)$ \\
\hline & Employee & $62(24.2)$ \\
\hline & Self-employed & $88(34.3)$ \\
\hline & Student & $59(23.2)$ \\
\hline & Manual worker & $22(8.4)$ \\
\hline & Unemployed & $10(4.0)$ \\
\hline & Housewife & $9(3.4)$ \\
\hline \multirow{7}{*}{ Primary caus } & Fall & $97(38.0)$ \\
\hline & Accident & 35 (13.8) \\
\hline & Sport & $47(18.5)$ \\
\hline & & \\
\hline & Convulsions & 51 (19.9) \\
\hline & Clash & $15(5.7)$ \\
\hline & While doing work & $10(4.0)$ \\
\hline \multirow{3}{*}{ Recurrence } & Yes & $58(22.6)$ \\
\hline & & \\
\hline & No & $198(77.4)$ \\
\hline \multirow{3}{*}{ First time } & Yes & $256(58.9)$ \\
\hline & & \\
\hline & No & $101(41.1)$ \\
\hline
\end{tabular}


Table 2. Mean \pm SD age and duration of immobility in the subjects $(N=256)$

\begin{tabular}{cc}
\hline Quantitative Variables & Mean \pm SD \\
\hline Age $(\mathrm{y})$ & $35.64 \pm 18.58$ \\
\hline Duration of immobility (day) & $15.5 \pm 4.61$ \\
\hline Duration of follow-up (y) & $3.1 \pm 1.26$ \\
\hline
\end{tabular}

Orthopedic Science

\section{Discussion}

Anterior dislocation is the most common shoulder dislocations, accounting for up to $97 \%$ of all. The main complication of anterior shoulder dislocation is its recurrence [14]. Therefore, the present study aimed to determine the factors related to the frequency of recurrent anterior dislocation of the recurrent shoulder in the
Orthopedic Ward of Kashani Hospital, Isfahan City, Iran, in 2017-2018.

Of 256 patients with their first dislocations, $22.6 \%$ experienced recurrent dislocations. The recurrence rate of dislocations in patients less than 20 years is $40 \%$ and in 20 to 40 years is $63 \%$. The highest recurrence rate of dislocation is reported in the age group of 20-40 years in the present study. In a similar study, Simonet et al. ex-

Table 3. Determining the relationship between demographic variables and recurrence of dislocation in the subjects

\begin{tabular}{|c|c|c|c|c|}
\hline \multirow{2}{*}{\multicolumn{2}{|c|}{ Variables }} & \multicolumn{2}{|c|}{ Recurrence } & \multirow{2}{*}{$\mathbf{P}$} \\
\hline & & Yes & No & \\
\hline \multirow{3}{*}{ Gender } & Male & $44.8 \%$ & $55.2 \%$ & \multirow{3}{*}{0.84} \\
\hline & & & & \\
\hline & Female & $40 \%$ & $60 \%$ & \\
\hline \multirow{3}{*}{ Age } & Less than 20 years & $40 \%$ & $60 \%$ & \multirow{3}{*}{0.02} \\
\hline & $20-40$ years & $60 \%$ & $40 \%$ & \\
\hline & $40-60$ years & $30 \%$ & $70 \%$ & \\
\hline \multirow{7}{*}{ Job } & Retired & - & $100 \%$ & \multirow{7}{*}{0.01} \\
\hline & Employee & $30 \%$ & $71 \%$ & \\
\hline & Self-employed & $46 \%$ & $53 \%$ & \\
\hline & & & & \\
\hline & Student & $42 \%$ & $57 \%$ & \\
\hline & Manual worker & $100 \%$ & 0 & \\
\hline & Unemployed & $100 \%$ & 0 & \\
\hline \multirow{7}{*}{ Primary cause } & Fall & $33 \%$ & $66 \%$ & \multirow{7}{*}{0.04} \\
\hline & Accident & $20 \%$ & $80 \%$ & \\
\hline & Sport & $100 \%$ & 0 & \\
\hline & & & & \\
\hline & Convulsions & $33 \%$ & $66 \%$ & \\
\hline & Clash & $33 \%$ & $66 \%$ & \\
\hline & While doing work & $100 \%$ & 0 & \\
\hline
\end{tabular}

Orthopedic Science

Chi-square test was used to find the correlation of the frequency distribution of comparisons; $\mathrm{P}<0.05$ indicates the significance of difference. 
Table 4. Determining the relationship between age and duration of immobility and recurrence of dislocation in the subjects

\begin{tabular}{cccc}
\hline \multirow{2}{*}{ Quantitative Variables } & \multicolumn{2}{c}{ Recurrence (Mean \pm SD) } & No \\
\cline { 2 - 4 } & Yes & $41.1 \pm 22.23$ & 0.03 \\
\hline Age (y) & $28.7 \pm 8.33$ & $19.31 \pm 4.20$ & 0.02 \\
\hline Duration of immobility (day) & $10.66 \pm 1.7$ & & Orthopedic Science
\end{tabular}

The independent $t$-test was used to compare the means of the variables; $\mathrm{P}<0.05$ indicates the significance of the test.

amined the prevalence of dislocations and the recurrence rate. In this study, the data of 116 patients out of 124 patients were examined. Based on the results, out of 116 patients, $38(33 \%)$ had recurrent dislocations: 21 out of 32 patients $(66 \%)$ were under 20 years old, 17 out of 43 patients $(40 \%)$ were 20 to 40 years old. Twenty-seven of the 33 young athletes $(82 \%)$ had re-dislocations, while only 8 of the 27 non-athletes $(30 \%)$ had recurrences of the dislocation at similar ages [15].

Based on the present study results, the recurrence rate of dislocation in the group of 20 to 40 years was significantly higher than in other groups. Several other studies confirming the present study's findings also showed that the recurrence rate of dislocation is higher in young patients than in the elderly [16-18]. Ramsey et al. reported that the high recurrence rate of anterior shoulder dislocation was higher in young patients [19]. Rhee et al. reported that these injuries occur at younger ages, with higher recurrence rates, and at shorter intervals between primary injury and recurrent instability events among athletes [20].

Based on other study results, no significant relationship was observed between the gender and recurrence of dislocation in the subjects; however, a significant difference was observed in the primary cause and type of occupation in recurrence of dislocation. Thus, the recurrence rate of manual workers and unemployed people was significantly higher than employees and retirees. Many different risk factors for recurrent anterior shoulder dislocations such as young age, participation in sports activities have been reported in other studies [21-24].

According to Porcellini et al. [25], age at first dislocation, male gender, and time from the first dislocation to surgery were significant risk factors for recurrence. However, in a prospective multicenter clinical study with 25 years of follow-up, no significant differences were found in relation to gender [26]. Because some patients were followed up by telephone, the level of hyper-laxity in the patients was not evaluated.

\section{Conclusion}

The recurrence rate of dislocation in the patients who suffered from dislocations for the first time was $22 \%$. Based on the results, the rate of recurrence of dislocation in the present study was lower than the rate of recurrence of dislocation in similar studies.

\section{Ethical Considerations}

\section{Compliance with ethical guidelines}

This study was approved by the Ethics Committee of the University of Isfahan University of Medical Science.

\section{Funding}

The paper was extracted from the $\mathrm{PhD}$. dissertation and the research project of Hossein Akbari Aghdam, Mohammad Dehghani, and Parisa Karimi at the Department of Orthopedic Surgery, Ayatollah Kashani Hospital, Faculty of Medicine, Isfahan University of Medical Sciences.

\section{Authors' contributions}

Conceptualization and Supervision: Hossein Akbari Aghdam and Mohammad Dehghani; Investigation, Writing - original draft: Parisa Karimi; Writing - review \& editing: All authors; Data collection and Data analysis: Hossein Akbari Aghdam, Mohammad Dehghani, and Parisa Karimi.

\section{Conflict of interest}

The authors declared no conflict of interest.

\section{Acknowledgments}

We would like to express our gratitude to the research council of medical school of Isfahan University of Medical Sciences and appreciate Kashani hospital for helping during this research. 


\section{References}

[1] Sofu H, Gürsu S, Koçkara N, Oner A, Issın A, Camurcu Y. Recurrent anterior shoulder instability: Review of the literature and current concepts. World J Clin Cases. 2014; 2(11):676-82. [DOI:10.12998/wjcc.v2.i11.676]

[2] Leroux T, Wasserstein D, Veillette C, Khoshbin A, Henry $\mathrm{P}$, Chahal $\mathrm{J}$, et al. Epidemiology of primary anterior shoulder dislocation requiring closed reduction in $\mathrm{On}$ tario, Canada. Am J Sports Med. 2014; 42(2):442-50. [DOI:10.1177/0363546513510391]

[3] Kane P, Bifano SM, Dodson CC, Freedman KB. Approach to the treatment of primary anterior shoulder dislocation: A review. Phys Sportsmed. 2015; 43(1):54-64. [DOI:10.1080/00 913847.2015.1001713]

[4] Nakhaei Amroodi M. Irreducible anterior shoulder dislocation associated with displaced fracture of the greater tuberosity: An analysis of seven cases. J Res Orthop Sci. 2015; 2(4):e4023. [DOI:10.17795/soj-4023]

[5] Huysmans PE, Haen PS, Kidd M, Dhert WJ, Willems JW. The shape of the inferior part of the glenoid: A cadaveric study. J Shoulder Elbow Surg. 2006; 15(6):759-63. [DOI:10.1016/j. jse.2005.09.001]

[6] An VVG, Sivakumar BS, Phan K, Trantalis J. A systematic review and meta-analysis of clinical and patient-reported outcomes following two procedures for recurrent traumatic anterior instability of the shoulder: Latarjet procedure vs. Bankart repair. J Shoulder Elbow Surg. 2016; 25(5):853-63. [DOI:10.1016/j.jse.2015.11.001]

[7] Owens BD, Campbell SE, Cameron KL. Risk factors for posterior shoulder instability in young athletes. Am J Sports Med. 2013; 41(11):2645-9. [DOI:10.1177/0363546513501508]

[8] Hong J, Huang Y, Ma C, Qu G, Meng J, Wu H, et al. Risk factors for anterior shoulder instability: A matched casecontrol study. J Shoulder Elbow Surg. 2019; 28(5):869-74. [DOI:10.1016/j.jse.2018.09.014]

[9] Wasserstein DN, Sheth U, Colbenson K, Henry PDG, Chahal J, Dwyer T, et al. The true recurrence rate and factors predicting recurrent instability after nonsurgical management of traumatic primary anterior shoulder dislocation: A systematic review. Arthroscopy. 2016; 32(12):2616-25. [DOI:10.1016/j.arthro.2016.05.039]

[10] Horst K, Von Harten R, Weber C, Andruszkow H, Pfeifer $\mathrm{R}$, Dienstknecht $\mathrm{T}$, et al. Assessment of coincidence and defect sizes in Bankart and Hill-Sachs lesions after anterior shoulder dislocation: A radiological study. Br J Radiol. 2014; 87(1034):20130673. [DOI:10.1259/bjr.20130673]

[11] Owens BD. Editorial commentary: Natural history of shoulder dislocation-is recurrence our only metric? Arthroscopy. 2016; 32(12):2626-7. [DOI:10.1016/j.arthro.2016.09.025]

[12] Olds M, Donaldson K, Ellis R, Kersten P. In children 18 years and under, what promotes recurrent shoulder instability after traumatic anterior shoulder dislocation? A systematic review and meta-analysis of risk factors. $\mathrm{Br} \mathrm{J}$ Sports Med. 2016; 50(18):1135-41. [DOI:10.1136/bjsports-2015-095149]

[13] Dala-Ali B, Penna M, McConnell J, Vanhegan I, Cobiella C. Management of acute anterior shoulder dislocation. Br J Sports Med. 2014; 48(16):1209-15. [DOI:10.1136/bjsports-2012-091300]
[14] Abrams R, Akbarnia H. Shoulder dislocations overview [Internet]. 2020 [2020 Nov 1]. In: StatPearls. Treasure Island (FL): StatPearls Publishing; 2021. [PMID]

[15] Simonet WT, Cofield RH. Prognosis in anterior shoulder dislocation. Am J Sports Med. 1984; 12(1):19-24. [DOI:10.11 77/036354658401200103]

[16] Magnuson PB, Stack JK. Recurrent dislocation of the shoulder. 1943. Clin Orthop Relat Res. 1991; (269):4-8. [DOI:10.1097/00003086-199108000-00002]

[17] Hovelius L. Shoulder dislocation in Swedish ice hockey players. Am J Sports Med. 1978; 6(6):373-7. [DOI:10.1177/0 36354657800600611]

[18] Adams JC. Recurrent dislocation of the shoulder. J Bone Joint Surg Br. 1948; 30(1):26-38. [DOI:10.1302/0301620X.30B1.26]

[19] Ramsey ML, Getz CL, Parsons BO. What's new in shoulder and elbow surgery. J Bone Joint Surg Am. 2010; 92(4):104761. [DOI:10.2106/JBJS.J.00072]

[20] Rhee YG, Cho NS, Cho SH. Traumatic anterior dislocation of the shoulder: Factors affecting the progress of the traumatic anterior dislocation. Clin Orthop Surg. 2009; 1(4):18893. [DOI:10.4055/cios.2009.1.4.188]

[21] Arciero RA, Wheeler JH, Ryan JB, McBride JT. Arthroscopic Bankart repair versus nonoperative treatment for acute, initial anterior shoulder dislocations. Am J Sports Med. 1994; 22(5):589-94. [DOI:10.1177/036354659402200504]

[22] Burkhart SS, De Beer JF. Traumatic glenohumeral bone defects and their relationship to failure of arthroscopic Bankart repairs: Significance of the inverted-pear glenoid and the humeral engaging Hill-Sachs lesion. Arthroscopy. 2000; 16(7):677-94. [DOI:10.1053/jars.2000.17715]

[23] Robinson CM, Kelly M, Wakefield AE. Redislocation of the shoulder during the first six weeks after a primary anterior dislocation: Risk factors and results of treatment. J Bone Joint Surg Am. 2002; 84(9):1552-9. [DOI:10.2106/00004623200209000-00007]

[24] Pagnani MJ, Dome DC. Surgical treatment of traumatic anterior shoulder instability in american football players. J Bone Joint Surg Am. 2002; 84(5):711-5. [DOI:10.2106/00004623200205000-00002]

[25] Porcellini G, Campi F, Pegreffi F, Castagna A, Paladini P. Predisposing factors for recurrent shoulder dislocation after arthroscopic treatment. J Bone Joint Surg Am. 2009; 91(11):2537-42. [DOI:10.2106/JBJS.H.01126]

[26] Hovelius L, Olofsson A, Sandström B, Augustini BG, Krantz $\mathrm{L}$, Fredin $\mathrm{H}$, et al. Nonoperative treatment of primary anterior shoulder dislocation in patients forty years of age and younger. A prospective twenty-five-year follow-up. J Bone Joint Surg Am. 2008; 90(5):945-52. [DOI:10.2106/JBJS.G.00070] 